\title{
Oxygen Equilibrium of Hemoglobin J Cape Town
}

\author{
Samuel Charache and Trefor Jenkins with the technical assistance of \\ MELODY F. WILDER \\ From the Department of Medicine, Johns Hopkins University School of \\ Medicine, Baltimore, Maryland 21205, and the Human Sero-Genetics Unit, \\ South African Institute for Medical Research, Johannesburg
}

\begin{abstract}
A в S T R A C T Polycythemia in carriers of hemoglobin $\mathrm{J}$ Cape Town or hemoglobin Chesapeake is thought to be produced by increased oxygen affinity of their blood. Both hemoglobins involve substitution of amino acid residue $\alpha$ FG-4. Measurements reported here, of the oxygen equilibrium of purified hemoglobin J Cape Town, permit direct comparison of the two hemoglobins. $\mathrm{J}$ Cape Town exhibits lower oxygen affinity, and greater heme-heme interaction, than Chesapeake; both exhibit normal Bohr effects. Substitution of one polar amino acid residue for another of opposite charge (arginine $\rightarrow$ glutamic acid) thus appears to create less disruption of the interface between $\alpha$ - and $\beta$-chains than substitution of a nonpolar residue (arginine $\rightarrow$ leucine).
\end{abstract}

\section{INTRODUCTION}

Some, but not all carriers of hemoglobin $\mathrm{J}$ Cape Town $(\mathrm{Hb} J),(\alpha 92(\mathrm{FG}-4) \mathrm{Glu})$ are polycythemic $(1,2)$. Oxygen affinity of a hemolysate containing $35 \% \mathrm{Hb} \mathrm{J}$ was increased, while the Bohr effect was normal, suggesting that polycythemia was produced by decreased delivery of oxygen to tissues (3). Heme-heme interaction in $\mathrm{Hb} \mathrm{J}$ was significantly decreased, with an $n$ value of 1.8. These findings were of great interest, for hemoglobin Chesapeake ( $\alpha 92 \mathrm{Leu}$ ), which also is produced by a mutation at FG-4, exhibits increased oxygen affinity and decreased heme-heme interaction $(n=$ 1.3) (4). We report here data on the oxygen equilibrium of purified $\mathrm{Hb} \mathrm{J}$, studied under the conditions used in previous studies of hemoglobin Chesapeake.

\section{METHOD}

Blood was collected in Johannesburg in ACD (acid citrate dextrose) solution under sterile conditions. It was shipped in ice to Baltimore and arrived in excellent condition. A

Received for publication 29 March 1971.

${ }^{1}$ Nagel, R. L., Q. H. Gibson, and T. Jenkins. Ligand binding in hemoglobin J Capetown. Submitted for publication.

${ }^{2}$ Charache, S., R. Briehl, and T. Jenkins. Unpublished observations. portion of the blood was used for studies of ligand binding and mobility in the ultracentrifuge. ${ }^{2}$ Portions of the remainder were removed over the next 2 wk, maintaining sterility at all times. Red cells were washed three times, hemolysates were prepared with toluene and distilled water, and the hemoglobin components were separated by starch block electrophoresis at $4^{\circ} \mathrm{C}$ (5). After electrophoresis, the eluted hemoglobin solution was passed through a $4 \times 40$ $\mathrm{cm}$ column of Sephadex G-25, which had been equilibrated with $0.1 \mathrm{M}$ phosphate buffer. Samples were adjusted to a concentration of $0.1 \mathrm{~g} / 100 \mathrm{ml}$, and oxygen affinity was measured at $10^{\circ} \mathrm{C}$, using a modification of the techniques of Allen, Guthe, and Wyman (6) and Riggs (7). Methemoglobin formation was monitored by measurement of optical density at $630 \mathrm{~m} \mu$; the only samples ( $\mathrm{pH}$ 6.8) which showed more than a very slight increase in OD were discarded.

\section{RESULTS}

Oxygen affinity of $\mathrm{Hb} \mathrm{J}$ was increased, and a normal Bohr effect was present (Fig. 1). Heme-heme interaction was decreased: the mean value of $n$ from nine series of measurements, calculated by the method of least squares, was 2.22 (SD 0.20). Data for $\mathrm{Hb} \mathrm{J}$ are compared with data for normal hemoglobin and $\mathrm{Hb}$ Chesapeake in Fig. 2: $\mathrm{Hb}$ Chesapeake has a lower p50 and a lower value of $n$ than $\mathrm{Hb} \mathrm{J}$.

\section{DISCUSSION}

Heme-heme interaction of purified $\mathrm{Hb} \mathrm{J}$ was not decreased to the degree found by Lines and McIntosh in a hemolysate of whole blood (3). The difference between their results and ours may be due to graphical summation of the properties of two hemoglobins with different affinities for oxygen: the true dissociation curve must be sinusoidal, since $\mathrm{Hb} \mathrm{J}$ plays a disproportionate role in oxygen binding at low oxygen tensions. Effects of the two hemoglobins might be resolved using a continuously recording oxygen electrode and linear coordinates (8); the small departure from linearity would not be noted when the logarithmic form of Hill's equation is utilized. 


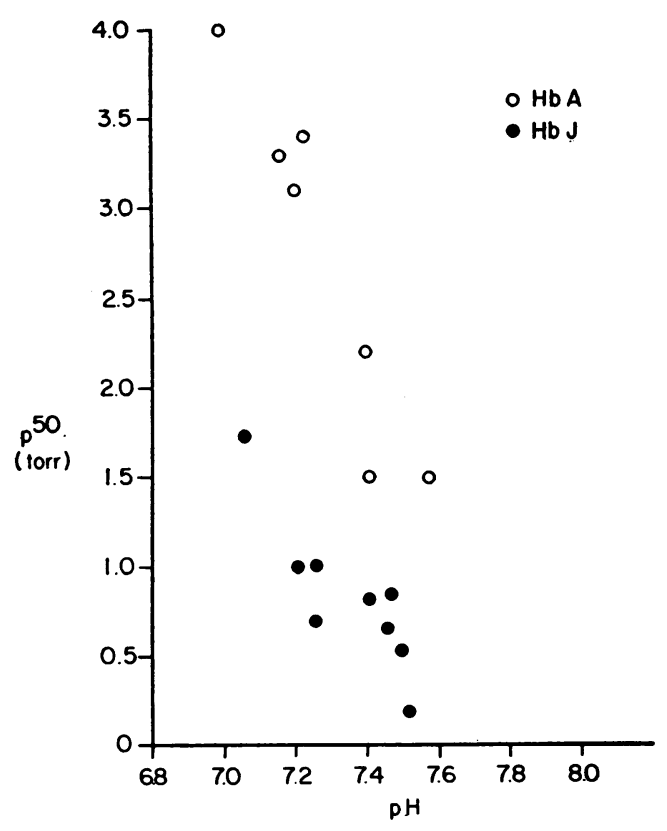

Figure 1 Bohr effect in hemoglobins A- and J-Cape Town. Each point represents the oxygen pressure required for half saturation of hemoglobin at $10^{\circ} \mathrm{C}$ in $0.1 \mathrm{M} \mathrm{PO}_{4}$ buffer at a given $\mathrm{pH}$. Points were derived from lines plotted according to Hill's equation $\left(\log \mathrm{S} / 1-\mathrm{S}=n \log \mathrm{P}_{\mathrm{O}_{2}}-n \log \mathrm{p} 50\right)$, where $\mathrm{S}$ is per cent saturation, $\mathrm{K}$ is a constant, and $n$ is related to the magnitude of heme-heme interaction. The oxygen affinity of $\mathrm{Hb} \mathrm{J}$ is higher than that of $\mathrm{Hb} \mathrm{A}$, but the magnitude of the Bohr effect appears to be normal.

All abnormal hemoglobins with amino acid substitutions at the $\alpha_{1} \beta_{2}$ interface between globin subunits have abnormal oxygen affinity, and $\mathrm{Hb} \mathrm{J}$ is no exception

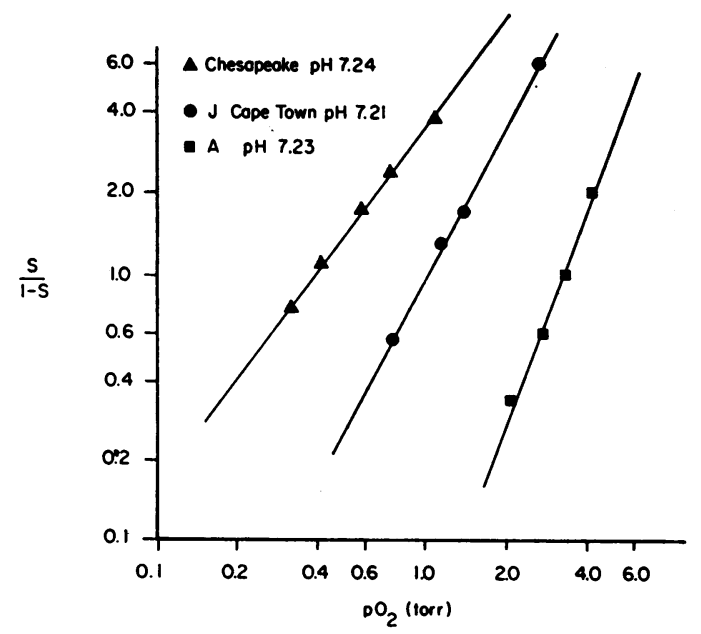

Figure 2 Oxygen affinity of hemoglobins Chesapeake, JCape Town, and A, plotted according to Hill's equation. Oxygen affinity of $\mathrm{Hb} \mathrm{J}$ is less than that of $\mathrm{Hb}$ Chesapeake, and heme-heme interaction is greater (Chesapeake: $n=1.3$; $\mathrm{J}: n=2.2$; A: $n=2.7$ ). Data for $\mathrm{Hb}$ Chesapeake are derived from Nagel, Gibson, and Charache (4).
[(9) and reference cited therein]. Analyses of X-ray diffraction data suggest that there are many differences between the structure of oxyhemoglobins $A$ and Chesapeake $(10)$. The oxygen equilibrium of $\mathrm{Hb} \mathrm{J}$ is less abnormal than that of $\mathrm{Hb}$ Chesapeake, as are a number of physical properties: electron-spin resonance spectra (11), reactivity with ligands, ${ }^{1}$ and sedimentation in the ultracentrifuge. ${ }^{2}$ Substitution of a polar residue by another of opposite charge ( $\mathrm{arg} \rightarrow \mathrm{glu}$ ) thus appears to create less disruption of the $\alpha_{1} \beta_{2}$ interface than does substitution by a nonpolar residue (arg $\rightarrow$ leu). Polycythemia produced by $\mathrm{Hb} \mathrm{J}$ is less impressive than that produced by $\mathrm{Hb}$ Chesapeake, as might be expected from these findings $(1,2,12)$.

\section{ACKNOWLEDGMENTS}

These studies were supported by grant HE 02799-14 from the National Institutes of Health, Bethesda, Md., and by the South African Council for Scientific and Industrial Research.

\section{REFERENCES}

1. Botha, M. D., D. Beale, W. A. Isaacs, and H. Lehmann. 1966. Haemoglobin J Cape Town- $\alpha_{2} 92$ arginine $\rightarrow$ glutamine $\beta_{2}$. Nature (London). 212: 792.

2. Jenkins, T., K. Stevens, E. Gallo, and H. Lehmann. 1968. A second family possessing haemoglobin $\mathrm{J} \alpha$ Cape Town. S. Afr. Med. J. $42: 1151$.

3. Lines, J. G., and R. McIntosh. 1967. Oxygen binding by haemoglobin J-Capetown $\left(\alpha_{2} 92\right.$ arg $\rightarrow$ gln $)$. Nature (London). 215: 297.

4. Nagel, R. L., Q. H. Gibson, and S. Charache. 1967. Relation between structure and function in Hemoglobin Chesapeake. Biochemistry. 6: 2395.

5. Kunkel, H. G., R. Ceppellini, U. Müller-Eberhard, and J. Wolf. 1957. Observations on the minor basic hemoglobin component in the blood of normal individuals and patients with thalassemia. J. Clin. Invest. 36: 1615.

6. Allen, D. W., K. F. Guthe, and J. Wyman, Jr., 1950. Further studies on the oxygen equilibrium of hemoglobin. J. Biol. Chem. 187 : 393.

7. Riggs, A. 1951. The metamorphosis of hemoglobin in the bullfrog. J. Gen. Physiol. 35: 23.

8. Duvelleroy, M. A., R. G. Buckles, S. Rosenkaimer, C. Tung, and M. B. Laver, 1970. An oxyhemoglobin dissociation analyzer. J. Appl. Physiol. 28: 227.

9. Perutz, M. F. 1970. Stereochemistry of cooperative effects in haemoglobin. Nature (London). 228: 726.

10. Greer, J., H. F. Bunn, C. Ho, and S. Charache. 1969. Further studies of the relation between structure and function in hemoglobin Chesapeake. Blood. 34: 838.

11. Baldassare, J. J., S. Charache, R. T. Jones, and C. Ho. 1970. Electron paramagnetic resonance studies of spinlabeled hemoglobins. II. Roles of subunit interactions and of intermediate structures in the cooperative oxygenation of hemoglobin and the results on hemoglobin Yakima, hemoglobin $\mathrm{J}$ Capetown and carboxy peptidases A and B treated hemoglobin A. Biochemistry. 9: 4707.

12. Charache, S., D. J. Weatherall, and J. B. Clegg. 1966. Polycythemia associated with hemoglobinopathy. J. Clin. Invest. 45: 813 . 